\title{
SHORT-TERM LOAD FORECASTING USING ANN TECHNIQUE
}

\author{
Samsher Kadir Sheikh ${ }^{1}$, M. G. Unde ${ }^{2}$ \\ ${ }^{1}$ Assistant Professor \& ${ }^{2}$ Professor, Electrical Dept PDVVP COE, Ahmednagar, India
}

\begin{abstract}
Load forecasting is the technique for prediction of electrical load. In a deregulated market it is much need for a generating company to know about the market load demand for generating near to accurate power. If the generation is not sufficient to fulfill the demand, there would be problem of irregular supply and in case of excess generation the generating company will have to bear the loss. Neural network techniques have been recently suggested for short-term load forecasting by a large number of researchers. This work studies the applicability of this kind of models. The work is intended to be a basis for a real forecasting application. First, a literature survey was conducted on the subject. Most of the reported models are based on the so-called MultiLayer Perceptron (MLP) network. There are numerous model suggestions, but the large variation and lack of comparisons make it difficult to directly apply proposed methods. It was concluded that a comparative study of different model types seems necessary. Several models were developed and tested on the real load data of a Finnish electric utility. Most of them use a MLP network to identify the assumed relation. We carried out shortterm load forecasting for P.D.V.V.P.COE, Ahmednagar college campus using ANN (Artificial Neural Network) technique ANN was implemented on MATLAB-10. MLP (Multi-layer Perceptions was made with input as days and hourly load. Hourly load means the hourly power consumption in college. Error was calculated as MAPE (Mean Absolute Percentage Error) and with error of about $0.956 \%$ this paper was successfully carried out. This paper can be implemented by any intensive power consuming company/ college for predicting the future load and would proved to be very useful tool while sanctioning the load
\end{abstract}

KEYWORD

Load forecasting, Artificial Neural Network, MLP, MAPE.

\section{INTRODUCTION}

The most used thing in today's world is energy. We use energy in various forms in our day to day life, electricity, refined oils, LPG, solar energy, wind energy, chemical energies in form of batteries and many other forms. Sometimes we are extravagant and sometimes we are careful. But to provide users uninterrupted supply of electricity there must be proper evaluation of present day and future demand of power. That's why we need a technique to tell us about the demand of consumers and the exact capability to generate the power and this need LOAD FORECASTING technique. It is used by power companies to anticipate the amount of power needed to supply the demand. It tells about the scenario of present and future load demand. It has many applications including energy purchasing and generation, load switching, contract evaluation, and infrastructure development. Load forecasting has become in recent years one of the major areas of research in electrical engineering. Load forecasting is however a difficult task. First, because the load series is complex and exhibits several levels of seasonality. Second, the load at a given hour is dependent not only on the load at the previous day, but also on the load at the same hour on the previous day and previous week, and because there are many important exogenous variables that must be considered [1]

\subsection{Necessity of LOAD FORECASTING}

Load forecasting is vitally important for the electric industry in the deregulated economy. It has many applications including energy purchasing and generation, load switching, contract evaluation, and 
International Journal of Engineering Sciences \& Emerging Technologies, Feb 2012. ISSN: 2231 - 6604 doi: 10.7323/ijeset/v1_i2_12 Volume 1, Issue 2, pp: 97-107 OIJESET

infrastructure development. A large variety of mathematical methods have been developed for load forecasting. Accurate models for electric power load forecasting are essential to the operation and planning of a utility company. Load forecasting helps an electric utility to make important decisions including decisions on purchasing and generating electric power, load switching, and infrastructure development. Load forecasts are extremely important for energy suppliers, ISOs, national institutions, and other participants in electric energy generation, transmission, distribution, and markets.

\subsection{Types of Load Forecasting Techniques Involved}

Load forecasts can be divided into three categories:

[i] Short-term forecasts: This is usually from one hour to one week.

[ii]Medium forecasts : This is usually from a week to a year.

[iii]Long-term forecasts: This is longer than a year.

The forecasts for different time horizons are important for different operations within a utility company. The natures of these forecasts are different as well. For example, for a particular region, it is possible to predict the next day load with an accuracy of approximately 1-3\%. However, it is impossible to predict the next year peak load with the similar accuracy since accurate long-term weather forecasts are not available. For the next year peak forecast, it is possible to provide the probability distribution of the load based on historical weather observations. It is also possible, according to the industry practice, to predict the so-called weather normalized load, which would take place for average annual peak weather conditions or worse than average peak weather conditions for a given area. Weather normalized load is the load calculated for the so-called normal weather conditions which are the average of the weather characteristics for the peak historical loads over a certain period of time. The duration of this period varies from one utility to another. Most companies take the last 25-30 years of data. Load forecasting has always been important for planning and operational decision. However, with the deregulation of the energy industries, load forecasting is even more important. With supply and demand fluctuating and the changes of weather conditions and energy prices increasing by a factor of ten or more during peak situations, load forecasting is vitally important for utilities. Short-term load forecasting can help to estimate load flows and to make decisions that can prevent overloading. Timely implementations of such decisions lead to the improvement of network reliability and to the reduced occurrences of equipment failures and blackouts. Load forecasting is also important for contract evaluations and evaluations of various sophisticated financial products on energy pricing offered by the market. In the deregulated economy, decisions on capital expenditures based on long-term forecasting are also more important than in a non-deregulated economy when rate increases could be justified by capital expenditure projects.

\subsection{Important Factors for Forecasts}

Consideration of various factors is the prerequisite for accurate forecasting of load. Time factor, past weather data, class of consumers, load demanded by the region in past, growth of the region, amount of load increased etc, these are the factors which play pivotal role in calculating the demand load.

For Short-term load forecasting several factors should be considered, such as

[i] Time factors,

[ii] Weather data, and

[iii] Possible customers' classes.

The medium- and long-term forecasts take into account

[i] The historical load

[ii] Weather data,

[iii]The number of customers in different categories,

[iv]The appliances in the area and their characteristics including age,

[v] The economic and demographic data and their forecasts,

[vi]The appliance sales data and other factors. 
International Journal of Engineering Sciences \& Emerging Technologies, Feb 2012. ISSN: 2231 - 6604 doi: 10.7323/ijeset/v1_i2_12 Volume 1, Issue 2, pp: 97-107 CIJESET

The time factors include the time of the year, the day of the week, and the hour of the day. There are important differences in load between weekdays and weekends. The load on different weekdays also can behave differently. For example, Mondays and Fridays being adjacent to weekends, may have structurally different loads than Tuesday through Thursday. This is particularly true during the summer time. Holidays are more difficult to forecast than non-holidays because of their relative infrequent occurrence. Weather conditions influence the load. In fact, forecasted weather parameters are the most important factors in short-term load forecasts.[2]

\section{Artificial NeUral Network}

ANN is usually formed from many hundreds or thousands of simple processing units, connected in parallel and feeding forward in several layers. Because of the fast and inexpensive personal computers availability, the interest in ANN's has blossomed in the current digital world. The basic motive of the development of the ANN is to make the computers do what a human being cannot do

\subsection{Benefits of ANN}

1. They are extremely powerful computational devices.

2. Massive parallelism makes them very efficient

3. They can learn and generalize from training data - so there is no need for enormous feats of programming.

4. They are particularly fault tolerant - this is equivalent to the "graceful degradation" found in biological systems.

5. They are very noise tolerant - so they can cope with situations where normal symbolic systems would have difficulty.

6. In principle, they can do anything a symbolic/logic system can do, and more.

\subsection{Working of Brain Replica of Artificial Neural Network}

ANN is relatively crude electronic models based on the neural structure of the human brain which basically learns from experience .Learning in biological systems involves adjustments to the synaptic connections that exist between the neurons. The basic building block of all biological brains is a nerve cell, or a neuron. A basic component of a neuron shows the various inputs to the network. It is represented by the mathematical symbol, $x(n)$. Each of these inputs is multiplied by a connection weight. These weights are represented by w (n)

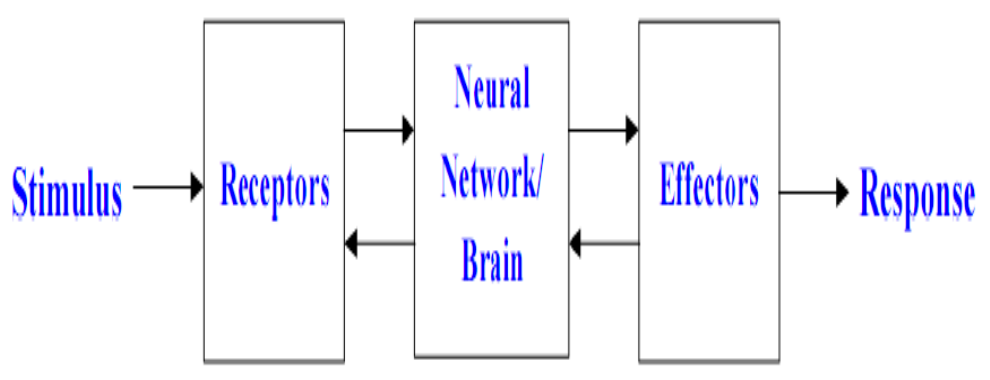

Fig :- 1Block diagram of Human Nervous system

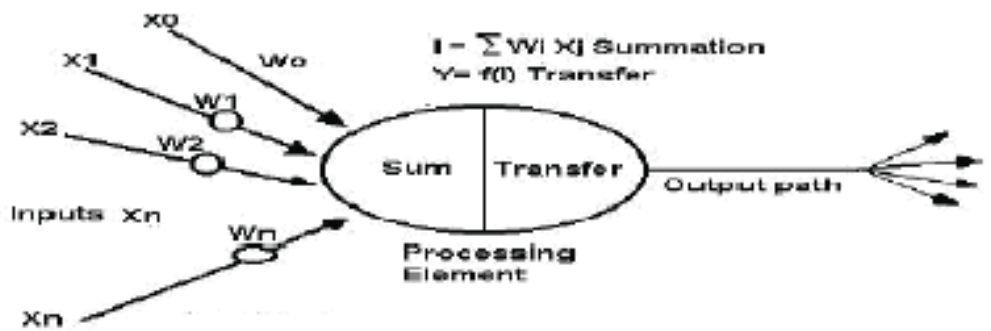

Fig :-2 working principle of ANN system

Above two figures shows similarity in the working principle of brain and ANN system. 
International Journal of Engineering Sciences \& Emerging Technologies, Feb 2012. ISSN: 2231 - 6604 doi: 10.7323/ijeset/v1_i2_12 Volume 1, Issue 2, pp: 97-107 CIJESET

\subsection{Multi-Layer Perception (MLP)}

Multi-Layer Perceptron (MLP) network is the most popular neural network type and most of the reported neural network STLF models are based on it .The MLP network consists of several layers of neurons. Each neuron in a certain layer is connected to each neuron of the next layer. There are no feedback connections.

\subsection{Identification of Input Data}

This technique uses 2 variables:

[i] The historical load demand and

[ii] Time for 24 hours.

The network learned through historical data to give the network input signals and desired outputs. To each input signal the network produced an output signal, and the learning aimed at minimizing the sum of squares of the differences between desired and actual outputs. The learning was carried out by repeatedly feeding the input-output patterns to the network. One complete presentation of the entire training set was called an epoch. The learning process was usually performed on an epoch-by-epoch basis until the weights stabilized and the sum of squared errors converged to some minimum value or goal .The other parameters were the learning rate $(\eta ́)$ and momentum factor $(\dot{\alpha})$. Both parameters were system dependent. The momentum factor caused the weight changes to be dependent on more than one input pattern. The useful range for this parameter was between 0 and 1. [3]

\section{ACTUAL IDENTIFICATION OF INPUT DATA}

This paper used two variables:

[i] The historical load demand, and

[ii] Time for 24 hours.

Historical load demand data of our college was used as a reference to get the profile of weekends.

Data was taken from January 17th 2011 until January 24th 2011. (1WEEK)

The selections of data were carried out according to the following steps in order to get good predictions:-

i) Separate the data by day:

_ Data Friday

- Data Saturday

_ Data Sunday

ii) Select the data without holiday

iii) Choose the best range of data to train

MATLAB can be trained by typing out the right profile or pattern for each day.

MATLAB 10 has been used by us carry out our work.

Based on the data we have plotted the graph shown below using Microsoft Excel 2007

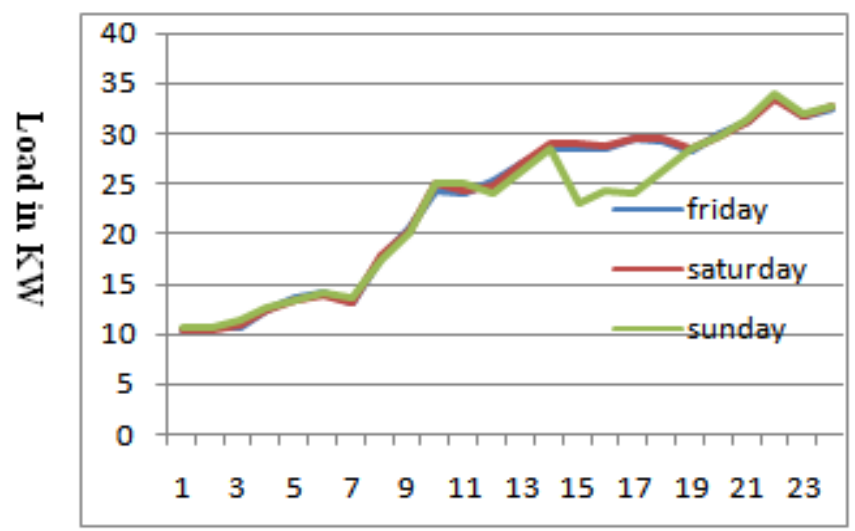

Time ih hrs

Fig:-3 This graph shows the actual variation of load for 24 hrs of Friday, Saturday and Sunday 
International Journal of Engineering Sciences \& Emerging Technologies, Feb 2012. ISSN: 2231 - 6604 doi: 10.7323/ijeset/v1_i2_12 Volume 1, Issue 2, pp: 97-107 CIJESET

Observation can be made that the load variation is mainly during $10 \mathrm{am}$ to $5 \mathrm{pm}$ i.e. working hour of college. Friday being the full day has the max load throughout the day while Saturday is half and Sunday is holiday.

\subsection{Implementation of ANN using MATLAB.10}

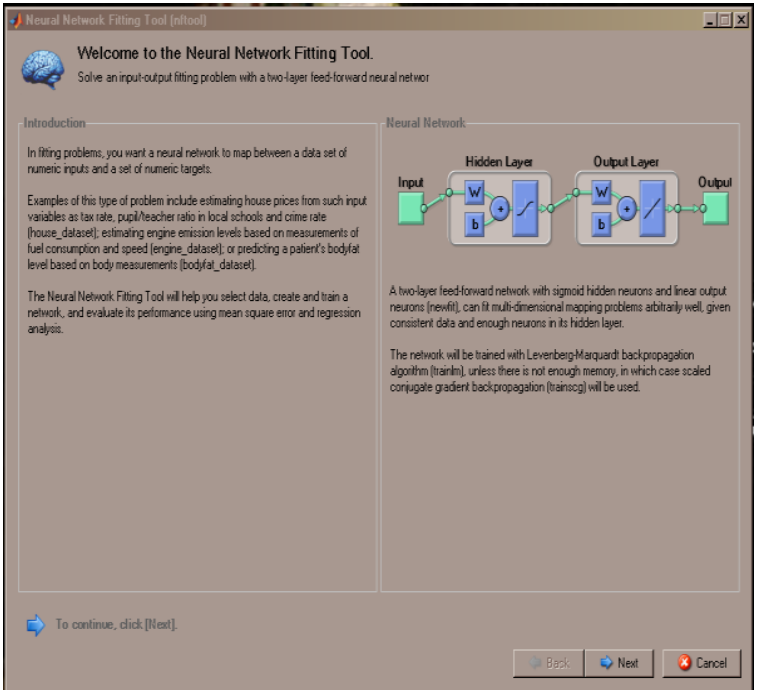

Fig 3.1 Open nftool in MATLAB.10

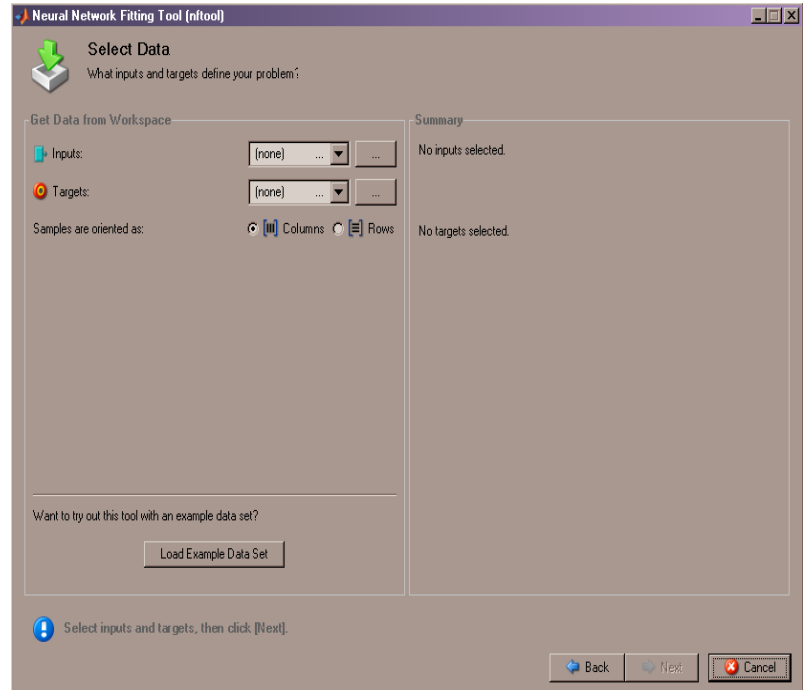

Fig;-3.2 Prepare input data and output data in Workspace. Import the prepare data from workspace

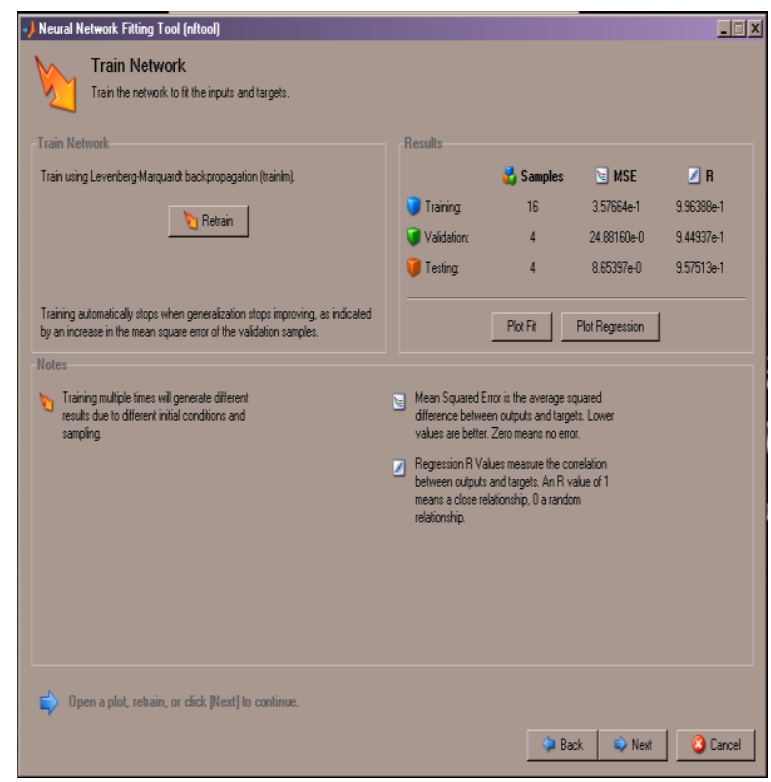

Fig :- 3.4 error Retrain

Fig:-3,3 Training validation and testing percentage can be set according to the need. In this paper Training was set to $70 \%$, Validation was $15 \%$ and Testing was $15 \%$

If error is high then to minimize the error Retrain is done

Then we can get plots of performance, Training state, Fit and Regression 
International Journal of Engineering Sciences \& Emerging Technologies, Feb 2012. ISSN: 2231 - 6604 doi: 10.7323/ijeset/v1_i2_12 Volume 1, Issue 2, pp: 97-107 OIJESET

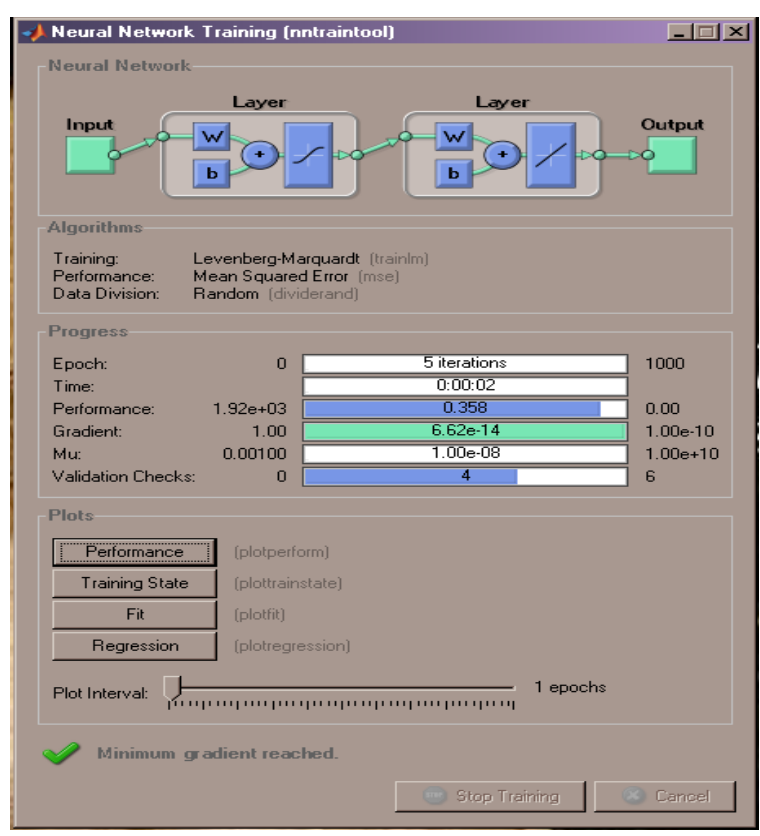

Fig :- 3.5 Training state, Fit and Regression.

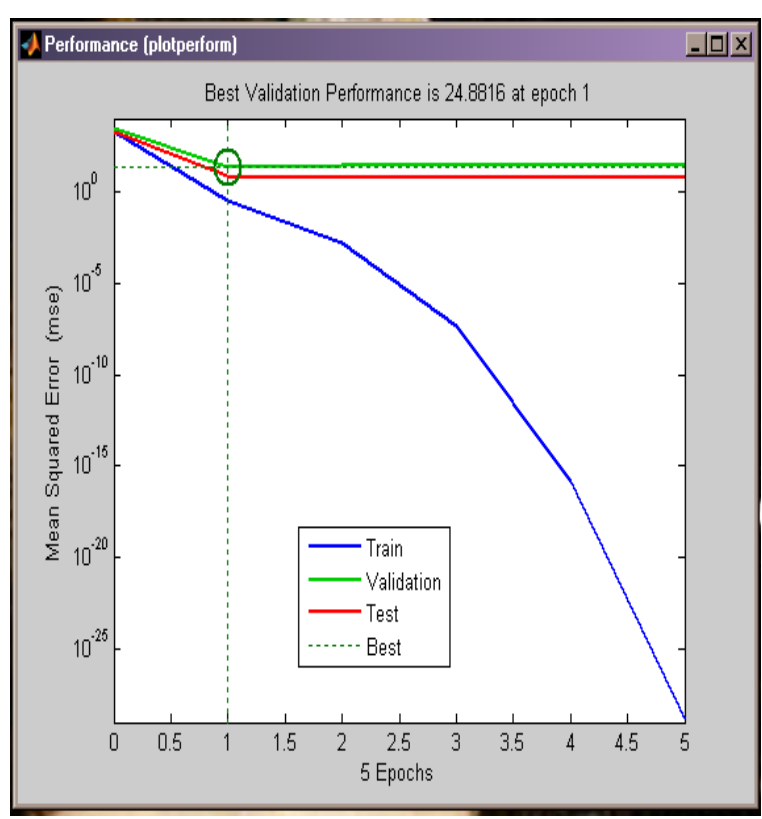

Fig:-3.6 This shows the performance plot for Sunday with 5 Epochs. This plot is Mean squared error vs Epochs.

Best Validation performance is 24.8816 at epoch 1.

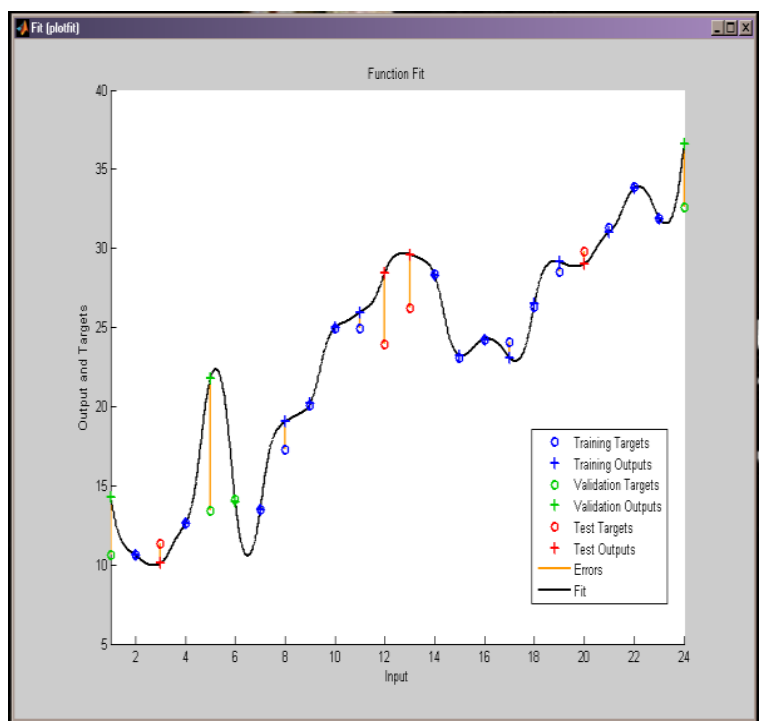

Fig :-3.7 This is the plot fit for output and targets Vs input. Errors are shown in the graph. This error is difference between actual data and predicted data.

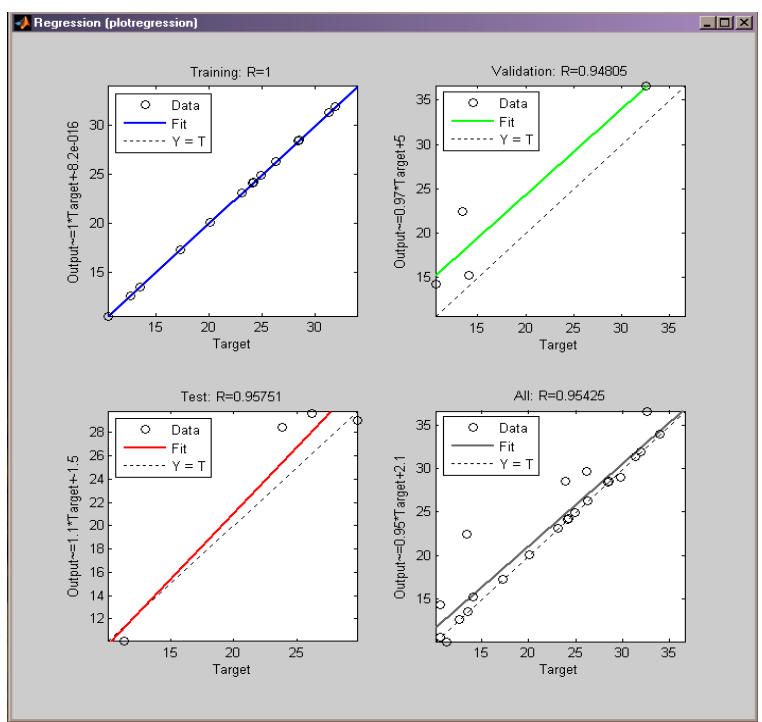

Fig 3.8 regression plot for Sunday similarly, various plots can be found for Saturday and Friday

The regression plot for Sunday is shown below. 
International Journal of Engineering Sciences \& Emerging Technologies, Feb 2012. ISSN: 2231 - 6604 doi: 10.7323/ijeset/v1_i2_12 Volume 1, Issue 2, pp: 97-107 CIJESET

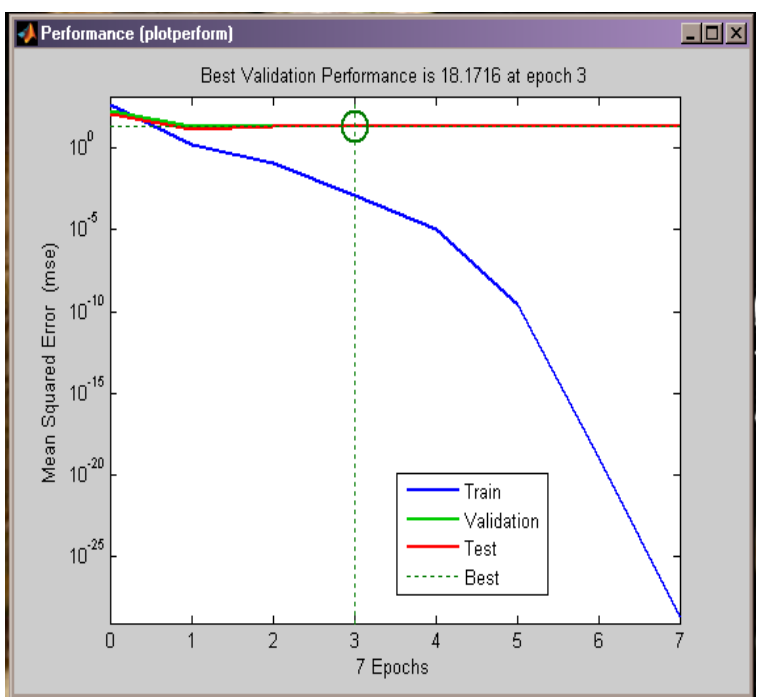

Fig 3.9:- Saturday

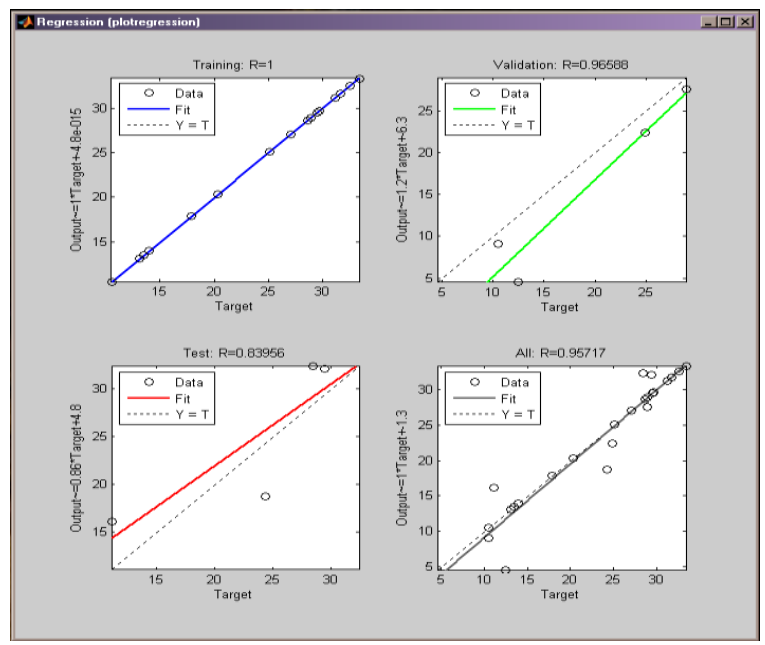

Fig3.11 for Saturday The regression plot shown.

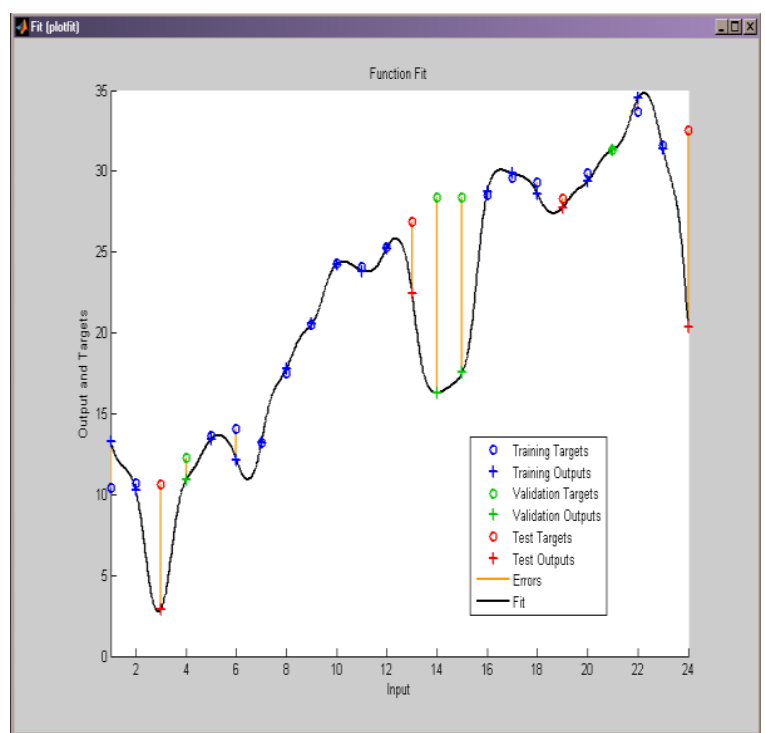

Fig 3.13for Friday

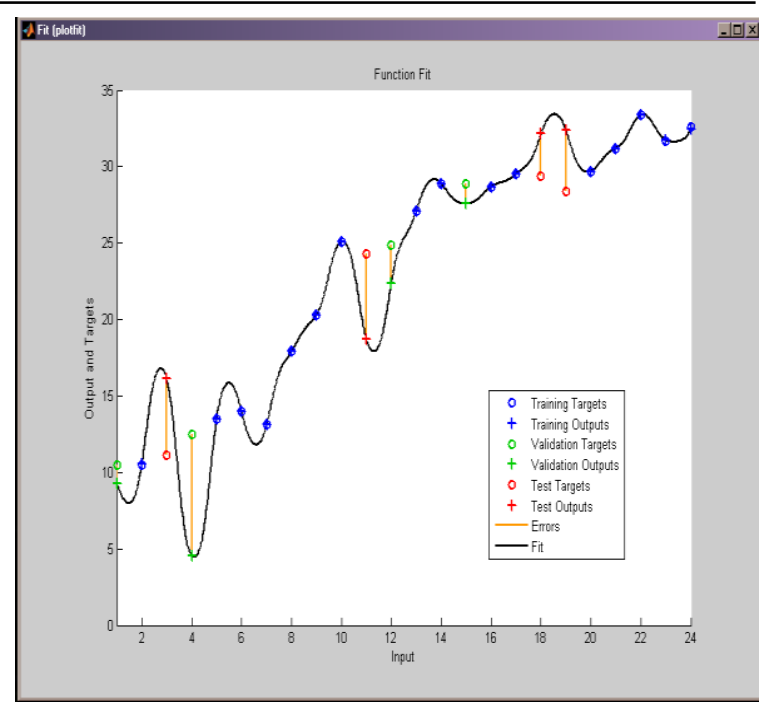

Fig3.10:- For Saturday

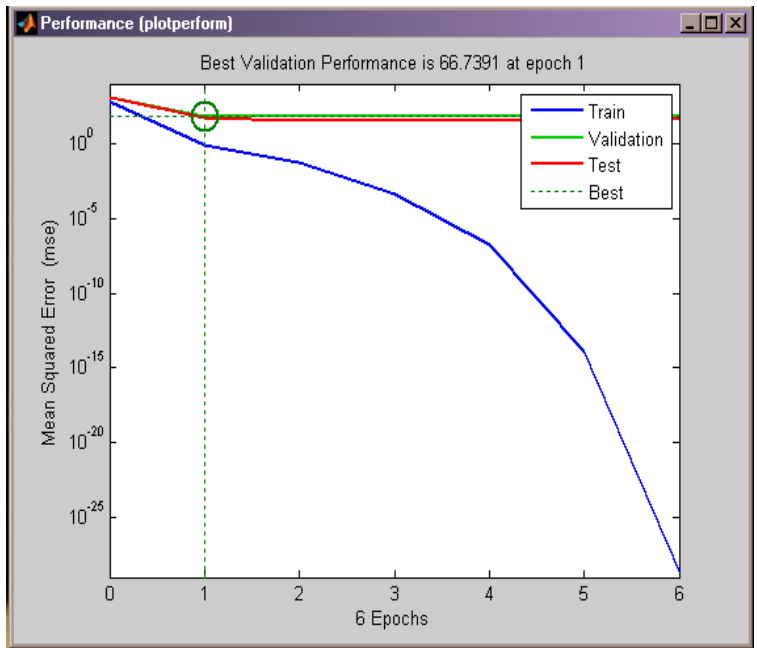

Fig3.12 for friday

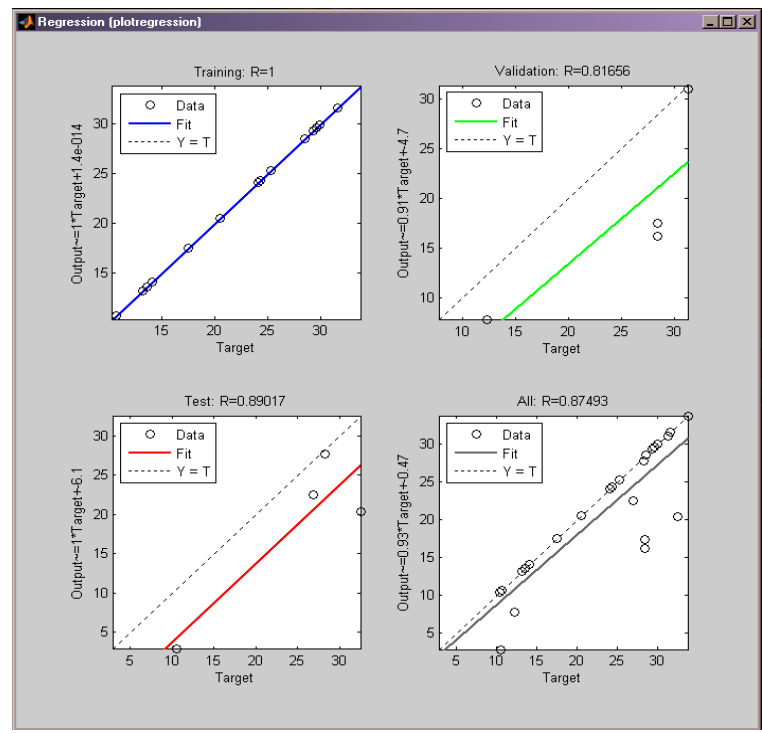

Fig3.14 for Friday The regression plot shown 
International Journal of Engineering Sciences \& Emerging Technologies, Feb 2012. ISSN: 2231 - 6604 doi: 10.7323/ijeset/v1_i2_12 Volume 1, Issue 2, pp: 97-107 OIJESET

\section{PROGRAM}

Generated $\mathbf{m}$-filefunction net $=$ create_fit_net(inputs,targets)

\%CREATE_FIT_NET Creates and trains a fitting neural network.

$\%$

$\%$ NET $=$ CREATE_FIT_NET(INPUTS,TARGETS) takes these arguments:

$\% \quad$ INPUTS - RxQ matrix of Q R-element input samples

$\%$ TARGETS - SxQ matrix of Q S-element associated target samples

$\%$ arranged as columns, and returns these results:

$\% \quad$ NET - The trained neural network

$\%$

$\%$ For example, to solve the Simple Fit dataset problem with this function:

$\%$

$\%$ load simplefit_dataset

$\%$ net = create_fit_net(simplefitInputs,simplefitTargets);

$\%$ simplefitOutputs $=\operatorname{sim}($ net, simplefitInputs $)$;

$\%$

$\%$ To reproduce the results you obtained in NFTOOL:

$\%$

$\%$ net $=$ create_fit_net(input 1, unnamed $)$;

$\%$ Create Network

numHiddenNeurons $=20 ; \%$ Adjust as desired

net $=$ newfit(inputs,targets,numHiddenNeurons);

net.divideParam.trainRatio $=70 / 100 ; \%$ Adjust as desired

net.divideParam.valRatio $=15 / 100 ; \%$ Adjust as desired

net.divideParam.testRatio $=15 / 100 ; \%$ Adjust as desired \% Train and Apply Network

[net,tr] = train(net,inputs, targets);

outputs $=\operatorname{sim}($ net,inputs);

$\%$ Plot

plotperf(tr)

plotfit(net,inputs,targets)

plotregression(targets,outputs [5]

\section{1) COMPARISONS OF ACTUAL AND PREDICTED RESULTS [6] [7]}

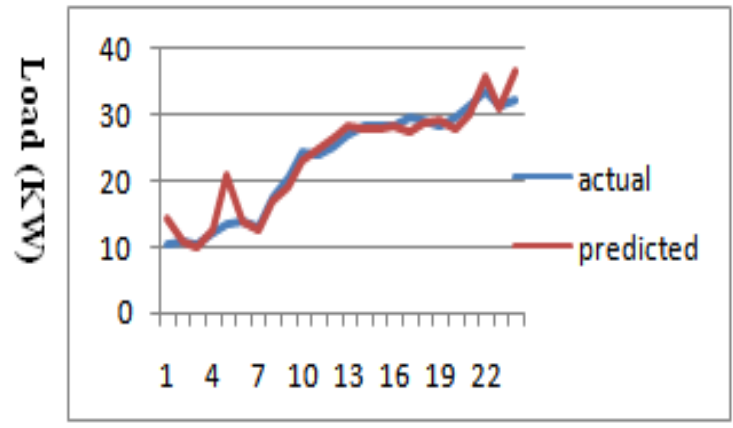

Time (Hrs)

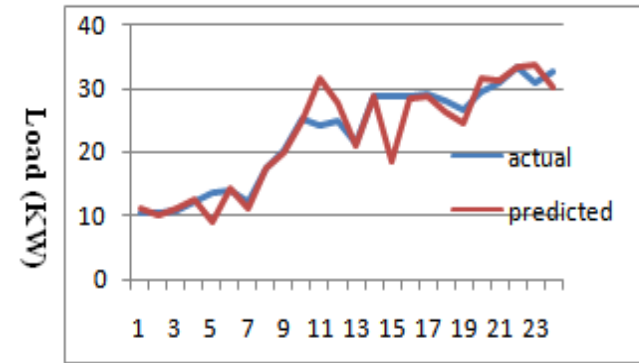

time in (Hrs)

Fig4.1 Friday

Fig4.2 Saturday 
International Journal of Engineering Sciences \& Emerging Technologies, Feb 2012. ISSN: 2231 - 6604 doi: 10.7323/ijeset/v1_i2_12 Volume 1, Issue 2, pp: 97-107 CIJESET

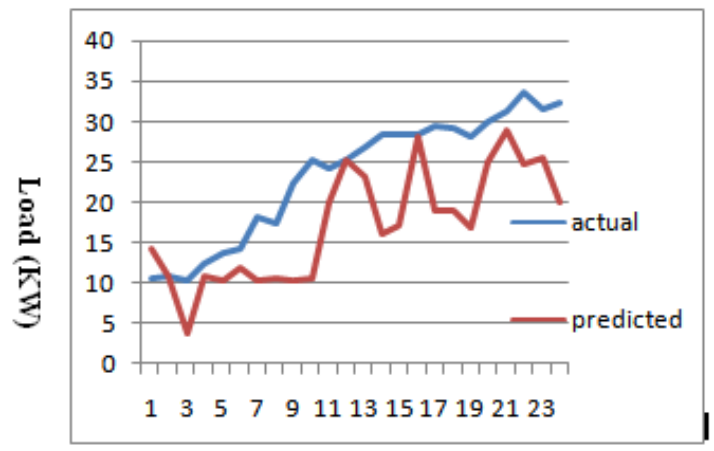

Time (Hrs)

Fig4.3 Sunday

\section{TABULATION OF RESULTS \& CALCULATION OF ERROR}

Calculation of Error as

\begin{tabular}{|c|c|c|}
\hline Hours & Actual load(kWh) & Predicted load(kWh) \\
\hline 1 & 10.4 & 14.3 \\
\hline 2 & 10.7 & 10.7 \\
\hline 3 & 10.26 & 3.7 \\
\hline 4 & 12.3 & 10.7 \\
\hline 5 & 13.6 & 10.3 \\
\hline 6 & 14.1 & 11.8 \\
\hline 7 & 18.2 & 10.2 \\
\hline 8 & 17.5 & 10.6 \\
\hline 9 & 22.5 & 10.4 \\
\hline 10 & 25.3 & 10.6 \\
\hline 11 & 24.1 & 20 \\
\hline 12 & 25.3 & 25.2 \\
\hline 13 & 26.9 & 23.3 \\
\hline 14 & 28.4 & 16.1 \\
\hline 15 & 28.4 & 17.2 \\
\hline 16 & 28.5 & 28.2 \\
\hline 17 & 29.6 & 19.1 \\
\hline 18 & 29.3 & 18.9 \\
\hline 19 & 28.3 & 17 \\
\hline 20 & 29.9 & 25 \\
\hline 21 & 31.3 & 29 \\
\hline 22 & 33.7 & 24.9 \\
\hline 23 & 31.6 & 25.7 \\
\hline 24 & 32.5 & 20.1 \\
\hline
\end{tabular}

\section{CONCLUSION}

We have carried out short- term load forecasting of our college and predicted the future load. Actual data was the actual energy consumed .We have used MATLAB.10 for prediction of load. The result of MLP network model used for one day ahead short term load forecast for the P.D.V.V.P. college of engineering, Ahmednagar shows that MLP network has a good performance and reasonable prediction accuracy was achieved for this model. Its forecasting reliabilities were evaluated by computing the mean absolute percentage error between the actual and predicted values.

We were able to obtain a Mean Absolute Percentage Error (MAPE) of $1.066 \%$ which represents the high degree of accuracy. The results suggest that ANN model with the developed structure can perform good prediction with least error and finally this neural network could be an important tool for short term load forecasting. 
International Journal of Engineering Sciences \& Emerging Technologies, Feb 2012. ISSN: 2231 - 6604 doi: 10.7323/ijeset/v1_i2_12 Volume 1, Issue 2, pp: 97-107 OIJESET

Error Calculation for Sunday,

$M A P E=\frac{\left(\sum\left|\frac{A C T U A L-P R E D I C T}{A C T U A L}\right|\right)}{N} X 100 \%$

MAPE $=\{[564.66-435] / 564.66\} * 100 / 24 \%$

$=0.956 \%$

Similarly calculation of error for Friday and Saturday can be done.

\begin{tabular}{|l|l|}
\hline Days & MAPE(\%) \\
\hline Friday & 1.279 \\
\hline Saturday & 0.963 \\
\hline Sunday & 0.956 \\
\hline
\end{tabular}

\section{FUTURE SCOPE}

Future studies on this work can incorporate additional information (such as customer class and season of the year) into the network so as to obtain a more representative forecast of future load. Network specialization (i.e. the use of one neural network for the peak periods of the day and another network for the hours of day) can also be experimented upon.

\section{REFERENCES}

[1] "Load Forecasting" Chapter 12, E.A Feinberg and Dora Genethlio, Page 269 - 285, from links: www.ams.sunysb.edu nd www.usda.gov

[2] Moghram, S. Rahman, "Analysis and Evaluation of Five Short-Term Load Forecasting Techniques," Proceedings of the IEEE Transaction on Power systems, pp. 1484-1491, Vol. 4,

[3] Application of Neural Network to Load Forecasting in Nigerian Electrical Power System by G.A. Adepoju, M.Sc.1, S.O.A Ogunjuyigbe, M.Sc.2, and K.O. Alawode, B.Tech.1

[4] One Hour Ahead Load Forecasting Using Artificial Neural Network for the Western Area of Saudi Arabia by A. J. Al-Shareef, E. A. ohamed, and E. Al-Judaibi

[5] Neural network toolbox for use with malab by Howard Demuth, Mark Beale, Martin Hogan

[6] Artificial Neural Network Approach short Term Load Forecasting for Illam Region by Mohsen Hayati, and Yazdan Shirvany

[7] Ho, K.-L., Y.-Y. Hsu, C-C. Yang, 1992, "short-term load forecasting using a multilayer neural network with an adaptive learning algorithm", IEEE Transactions on Power Systems, Vol. 7, No. 1, February 1992, pp. 141-148.

[8] Gross, G., F. D. Galiana, 1987, "Short-term load forecasting", Proceedings of the IEEE, Vol. 75, No. 12, December 1987, pp. 1558-1573.

[9] Gupta, P. C. and K. Yamada, 1972, "Adaptive short-term load forecasting of hourly loads using weather information", IEEE Transactions on Power Apparatus and Systems, Vol. PAS-91, No. 5, Sept./Oct. 1972, pp. 2085-2094.

[10] Hagan, M. T. and S. M. Behr, 1987, "The time series approach to short term load forecasting", IEEE Transaction on Power Systems, Vol. PWRS-2, No. 3, August 1987, pp, 785-791.

[11] Papalexopoulos, A. D., T. C. Hesterberg, 1990, "A regression-based approach to short-term system load forecasting", IEEE Transactions on Power Systems, Vol. 5,No. 4, November 1990, pp. 1535-1547.

\section{Authors}

Samsher Kadir Sheikh was born in Shegaon (India) on July15th 1968 \& working as Assistant Professor (Electrical Engineering Department) in P.D.V.V.P College of Engineering, Ahmednagar (M.S) India.He has completed graduation from Amravati University (M.S) India in 1995. He also completed his post graduation in Electrical Power System from Pune University (M.S) India. Presently he is pursuing PhD in Power system from NIMS University, Rajasthan .Now he is currently working on sugar cogeneration, power deregulation in power system \& neural network etc.

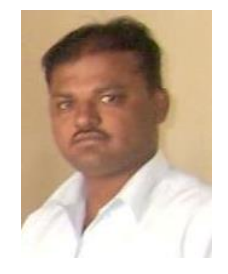


International Journal of Engineering Sciences \& Emerging Technologies, Feb 2012. ISSN: 2231 - 6604 doi: 10.7323/ijeset/v1_i2_12 Volume 1, Issue 2, pp: 97-107 CIJESET

M.G. Unde is working as Professor in Electrical Engineering Deptt..at Pad. Dr. Vithalrao Vikhe Patil College of Engineering, Ahmednagar from last 24 years. He has completed his Graduate degree B.E. Elect. In 1986 from Government College of engineering Pune and completed Masters Degree M.E. Power System in 1998 from the same college. Presently ,he is a Ph.D. research scholar of Pune university. His research interest is power system analysis and power system grounding design and analysis. Electrical machines, matlab programming, neural network etc.

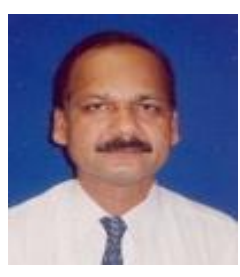

